\title{
Safety Profile Based on Concordance of Nonclinical Toxicity and Clinical Adverse Drug Reactions for Blood Cancer Drugs Approved in Japan
}

\author{
Sachie Kubota ${ }^{1}$ (D) Kazuyuki Saito ${ }^{2} \cdot$ Shunsuke Ono $^{3} \cdot$ Yasuo Kodama $^{1}$
}

Published online: 19 December 2016

(C) The Author(s) 2016. This article is published with open access at Springerlink.com

\begin{abstract}
Background In drug development, animal toxicology data are very important for the evaluation of clinical safety. We quantitatively assessed the safety profiles of blood cancer drugs approved in Japan from category I (high) to V (low). We examined the ratios of drug exposure in animals at the no observed adverse effect level to those in humans at the expected therapeutic dose. In addition, qualitative analysis of the relationship between toxicological findings and adverse drug reactions (ADRs) is one of the primary approaches for determining the risk-benefit profile of a pharmaceutical. This study thus aimed to evaluate the potential of nonclinical safety assessments for predicting ADRs in humans.

Methods We examined toxicological findings at the lowest observed adverse effect level and ADRs in pivotal clinical studies. We calculated concordance rates as the ratio of the number of concordant ADRs to all ADRs.

Results Twenty-seven drugs were eligible for analysis. Concordance rates ranged from 0 to $84.8 \%$. No significant differences were observed in concordance rates between antibodies (median 14.3\%) and small molecules (median $18.5 \%)$. There was a significant correlation between
\end{abstract}

Sachie Kubota

dp14-002@jiu.ac.jp

1 Laboratory of Pharmaceutical Regulatory Science, Graduate School of Pharmaceutical Sciences, Josai International University, 1 Gumyo, Togane, Chiba 283-8555, Japan

2 Department of Development Strategy, National Center for Child Health and Development, Setagaya-ku, Tokyo, Japan

3 Laboratory of Pharmaceutical Regulatory Science, Graduate School of Pharmaceutical Sciences, The University of Tokyo, Bunkyo-ku, Tokyo, Japan concordance rates and quantitative safety profiles $(p=0.047)$, suggesting that some drugs with low safety profiles (categories III, IV, or V) have high concordance rates.

Conclusion The results suggested that ADRs in clinical trials could be predicted based on toxicity data obtained in animal tests, especially for some drugs with a low quantitative safety profile.

\section{Key Points}

Qualitative analysis of the relationship between toxicological findings and adverse drug reactions (ADRs) is one of the primary measures for determining the risk-benefit profile of a pharmaceutical.

We evaluated the potential of nonclinical safety assessments for predicting ADRs in humans on blood cancer drugs approved in Japan.

The results suggested that ADRs in clinical trials could be predicted on the basis of toxicity data obtained in animal tests.

\section{Introduction}

Nonclinical data play a fundamental role in new drug development; they can be used to assess potential safety risks. The International Conference on Harmonisation (ICH) M3(R2) recommends that nonclinical safety studies should be adequate to characterize potential adverse effects 
that might occur under the conditions of the clinical trial to be supported [1]. It also states that clinical trials defined by ICH E8 should be extended based on the demonstration of adequate safety in previous clinical trial(s), as well as on additional nonclinical safety information [1, 2]. Human pharmacology studies with biomarkers conducted at the early clinical phases do not play a key role for safety estimation in therapeutic exploratory and/or therapeutic confirmatory studies in Japanese new drug applications (NDAs) [3]; therefore, animal toxicology data are useful for the prediction of safety profiles during the late clinical phases.

As one of the primary measures for determining the risk-benefit profile of a pharmaceutical, we recently conducted a study to evaluate the quantitative safety profiles of blood cancer drugs approved in Japan [4]. We examined safety indices obtained using the ratio of drug dose/exposure in animals at the no observed adverse effect level (NOAEL) to that in humans at the expected therapeutic dose. We used data from toxicokinetic studies indispensable for safety assessment as stated in ICH S3A [5]. We categorized quantitative safety profiles into five types, from I (high) to V (low), and found that although there were some drugs for blood cancer treatment with low quantitative safety profiles (categories III, IV, and V), the safety profiles of those drugs were not discussed in the NDA dossiers [4]. In the regulatory reviews for drug approval, quantitative safety profiles can provide a certain amount of information for the evaluation of the risk-benefit balance. In addition, it is important to assess drug safety using qualitative aspects by comparing nonclinical toxicology findings and adverse drug reactions (ADRs). However, there have been relatively few attempts to methodically assess the correlation between toxicity levels caused by the same drugs in animals and humans.

Igarashi et al., at the Japanese Pharmaceutical Manufacturers Association (JPMA), investigated published papers on general pharmacological studies and the clinical adverse reactions observed during new drug development [6]. They demonstrated that tests of cardiovascular functions, spontaneous locomotor activity, and intestinal transport are of considerable value in predicting ADRs. Furthermore, Olson et al. revealed that $71 \%$ of ADRs were observed in animals for the same target organ and the hematological, gastrointestinal, and cardiovascular ADRs were highly concordant [7]. However, evidence supporting the prediction of or extrapolation to human toxicities from the results of animal toxicology studies is scarce, and there is no consensus on this matter. Against this background, our primary objective in this study was to evaluate the potential of nonclinical safety assessments for predicting ADRs in humans treated with blood cancer drugs.

\section{Methods}

\subsection{Data Source}

We first reviewed data from drugs for blood cancer because severe adverse reactions were observed during clinical development and post-marketing surveillance of anticancer drugs. Moreover, the number of new molecular entities (NMEs) in this therapeutic area was suitable for this examination as a starting point and this group contained not only small-molecule drugs but also macromolecular drugs such as antibody drugs. Drugs for blood cancer approved in Japan from September 1999 to November 2016 as NMEs were analyzed. NOAEL, maximum approved dose, exposure levels at NOAEL and maximum approved dose, lowest observed adverse effect level (LOAEL), toxicological findings obtained at LOAEL, and ADRs were extracted from NDA review reports by the Ministry of Health, Labor and Welfare (MHLW) (until March 2004), the Pharmaceuticals and Medical Devices Agency (PMDA) (from April 2004), the common technical document (CTD) [8] by marketing authorization holders, package inserts, and interview forms available on the PMDA website [27]. Data were obtained in accordance with Japanese domestic regulations such as Good Clinical Practice [9] and Good Laboratory Practice [10] guidelines complying with the Pharmaceutical Affairs Law. Of the 539 NMEs identified, 28 drugs for blood cancer were identified for analysis (Table 1).

\subsection{Data Handling}

\subsubsection{Safety Index}

Safety indices are obtained from the ratio of doses and exposure levels in animals to those in humans. The safety index by dose (SI-D), safety index by maximum plasma

Table 1 NMEs for blood cancer analyzed in this study

Alemtuzumab Anagrelide hydrochloride hydrate Azacitidine

Bendamustine hydrochloride Bexarotene Bortezomib

Bosutinib Brentuximab vedotin Cladribine

Clofarabine Dasatinib hydrate Fludarabine phosphate

Gemtuzumab ozogamicin Ibritumomab tiuxetan Ibrutinib

Imatinib mesylate Lenalidomide hydrate Mogamulizumab

Nelarabine Nilotinib hydrochloride hydrate Ofatumumab

Panobinostat lactate Pomalidomide Rituximab

Ruxolitinib phosphate Tamibarotene Thalidomide

Vorinostat

NMEs new molecular entities 
concentration $\left(C_{\max }\right)$ [SI-C], and safety index by area under the plasma concentration-time curve (AUC) [SI-A] were calculated according to the following equations [4].

SI-D = NOAEL $(\mathrm{mg} / \mathrm{kg} /$ day $) /$ maximum approved dose (mg/kg/day)

$\mathrm{SI}-\mathrm{C}=C_{\max }$ at NOAEL $(\mu \mathrm{g} / \mathrm{mL}) / C_{\max }$ at maximum approved dose $(\mu \mathrm{g} / \mathrm{mL})$

$\mathrm{SI}-\mathrm{A}=\mathrm{AUC}$ at NOAEL $(\mu \mathrm{g} \cdot \mathrm{h} / \mathrm{mL}) / \mathrm{AUC}$ at maximum approved dose $(\mu \mathrm{g} \cdot \mathrm{h} / \mathrm{mL})$.

\subsubsection{Quantitative Safety Profile}

The quantitative safety profile of each drug was assessed if both SI-D and SI-C or SI-A were available. The safety profiles fell into five categories based on the safety indices (Fig. 1): profile 1, SI-D >1.0 and SI-C or SI-A >1.0; profile II, SI-D $\approx 1.0$ and SI-C or SI-A $\approx 1.0$; profile III, SI-D $>1.0$ and SI-C or SI-A $<1.0$; profile IV, SI-D $<1.0$ and SI$\mathrm{C}$ or SI-A $>1.0$; and profile V, SI-D $<1.0$ and SI-C or SI-A $<1.0$ [4].

These categories comprise one approach to clarify safety characteristics including the balance between safety index by dose and that by exposure. Safety profile I shows that both dose and exposure levels for animals exceed those for humans; therefore, it is interpreted that there is a certain safety margin for a drug categorized in safety profile I, while a drug in safety profile $\mathrm{V}$ has no safety margin for either dose or exposure levels.

\subsubsection{Collection of Nonclinical Toxicological Findings and ADRs}

\subsubsection{Drugs for Which Toxicological Findings at LOAEL} Are Available Nonclinical toxicological findings at LOAEL for each drug were collected from the same nonclinical study mentioned in our previous report [4], that is, the study that gave the smallest NOAEL. To compare the toxicological findings with ADRs, names and the number of ADRs of $\geq$ grade 3 were obtained from the clinical studies defined as pivotal. The grades were based on National Cancer Institute-Common Toxicity Criteria Version 2.0 [11], Common Terminology Criteria for Adverse Events (CTCAE) Version 3.0 [12], and CTCAE Version 4.0 [13]. In cases where the grades of severity were categorized as mild, moderate, and severe, the severe grade was considered to be $\geq$ grade 3 . Prioritization of pivotal studies used for analysis is shown in Table 2. We placed the utmost importance on studies with Japanese patients. If phase III data of Japanese patients were not obtained, phase II studies with Japanese patients were selected. In the case that no Japanese patient data were available other than a phase I study, foreign clinical data for which extrapolation to the Japanese population had been accepted based on ICH E5 [14] were used. As there was one drug (gemtuzumab ozogamicin) for which ADRs were not available in the source documents, adverse events (AEs) were substituted for ADRs.
Fig. 1 Quantitative safety profile. NOAEL no observed adverse effect level
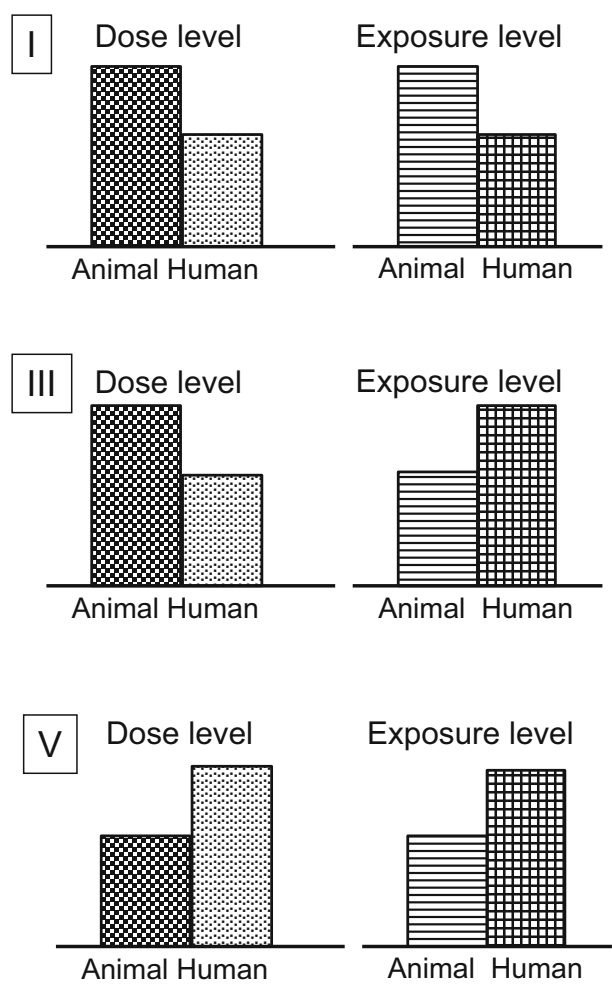

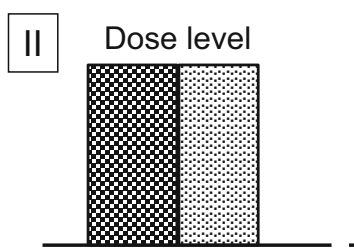

Animal Human
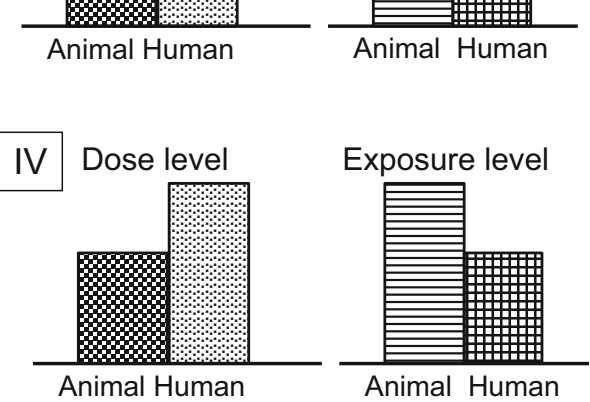

NOAEL

Maximum approved dose

Exposure at NOAEL

Exposure at Maximum approved dose 
Table 2 Handling of pivotal studies

\begin{tabular}{ll}
\hline Priority & Clinical study \\
\hline 1 & $\begin{array}{c}\text { The Japanese phase III study submitted as formal } \\
\text { documents }\end{array}$ \\
2 & The Japanese phase II study submitted as formal documents \\
3 & $\begin{array}{c}\text { Phase II data from the Japanese phase I/II study submitted } \\
\text { as formal documents }\end{array}$ \\
4 & The Japanese phase I/II study submitted as formal \\
& documents, if the number of events of each ADR was not \\
& counted by phase I and II separately \\
5 & Multi-regional phase III study including Japan submitted as \\
& formal documents \\
6 & Multi-regional phase II study including Japan submitted as \\
& formal documents \\
7 & Foreign phase III study submitted as formal documents
\end{tabular}

$A D R$ adverse drug reaction

${ }^{a}$ If there were two or more studies, the study with the largest number of subjects was selected

\subsubsection{Drugs for Which Toxicological Findings at LOAEL} Are Not Available If no toxicological study at a dose over NOAEL had been performed and toxicological findings at LOAEL were not available, nontoxic observations at NOAEL were collected. However, because observations at NOAEL were not considered as toxicity changes, it is not appropriate to compare such data with ADRs with a severe grade. For such drugs, clinical ADRs $\leq$ grade 1 were taken for comparison.

\subsubsection{Concordance of ADRs and Toxicological Findings}

An ADR reported in a clinical study was considered concordant with a nonclinical toxicological finding when the same finding was made in a human and an animal, or similar observations were made for similar organs $[6,7,15,16]$ (Table 3 ). Concordance rate was calculated as follows:

\subsubsection{Drugs for Which Toxicological Findings at LOAEL} Are Available Concordance rate $(\%)=$ (number of ADRs or AEs of $\geq$ grade 3 that are concordant with toxicological findings at LOAEL/total number of ADRs or AEs of $\geq$ grade 3$) \times 100$.

\subsubsection{Drugs for Which Toxicological Findings at LOAEL} Are Not Available Concordance rate $(\%)=$ (number of ADRs or AEs of $\leq$ grade 1 that are concordant with nontoxic observations at NOAEL/total number of ADRs or AEs of $\leq$ grade 1$) \times 100$.

\subsection{Statistical Analysis}

The SPSS software Version 23 (IBM, Armonk, NY, USA) was used to perform statistical analysis of the collected data. Comparisons were performed by the Mann-Whitney $U$ test. Regarding the association between two variables measured on at least an ordinal scale, the Spearman rankorder correlation coefficient was used. A $p$ value of $<0.05$ was considered statistically significant.

\section{Results}

Of the 28 drugs for blood cancer, 27 were eligible for analysis. Ibritumomab tiuxetan was excluded because the lack of data prevented calculation of the safety index. NOAEL, LOAEL, and clinical studies selected for the analysis are listed in Table 4 . Table 5 shows the concordance rate, administration route, drug type, species, and quantitative safety profile for each drug. The concordance rate of bosutinib was not calculated because of the lack of information on the severity of ADRs. The concordance rate of each System Organ Class (SOC) categorized by CTCAE is listed in Table 6. ADRs that were concordant with nonclinical observations in blood lymphatic system disorders and investigations were observed for many drugs, that is, 16 and 15 out of 26 drugs, respectively.

The mean concordance rate of 26 drugs excluding bosutinib was $23.9 \%$ (median: $18.5 \%$ ), with a range of $0-84.8 \%$. When stratified by the drug type, the mean concordance rates of small-molecule drugs and antibody drugs were $24.1 \%$ (median $18.5 \%$ ) and $23.3 \%$ (median $14.3 \%)$, respectively. There was no significant difference between them $(p=0.839$; Fig. 2$)$. The mean concordance rates of drugs with nonclinical data for rodents, non-rodents, oral drugs, and injectable drugs were $24.7 \%$ (median 24.3\%), 23.6\% (median 16.7\%), 16.4\% (median: $6.8 \%$ ), and $31.4 \%$ (median $21.8 \%$ ), respectively (Table 5). No significant differences between concordance rates were observed based on species (rodent vs. non-rodent; $\quad p=0.935)$ and administration route $(p=0.169)$.

The mean concordance rates of drugs excluding bosutinib by quantitative safety profile [five types; from I (high) to $\mathrm{V}$ (low)] were $7.4 \%$ (I), $18.4 \%$ (III), and $37.0 \%$ (V) (Table 5). (No drug was categorized into II in this study. Bosutinib was categorized into IV, but its concordance rate was not calculable.) The concordance rate and quantitative safety profile were weakly correlated (Spearman's $r=0.448, p=0.047$; Fig. 3). 
Table 3 Toxicological findings in animals considered concordant with ADRs in humans

\begin{tabular}{ll}
\hline ADRs & Concordant toxicological findings in \\
\hline Infections and infestations & \\
Neutropenic infection & Neutrophil count $\downarrow$ \\
Blood and lymphatic system disorders & \\
Erythropenia & RBC count $\downarrow$, reticulocyte count $\downarrow$ \\
Febrile neutropenia & Neutrophil count $\downarrow$ \\
Leukopenia & WBC count $\downarrow$ \\
Lymphocytopenia & Lymphocyte count $\downarrow$ \\
Neutropenia & Neutrophil count $\downarrow$ \\
Thrombocytopenia & Platelet count $\downarrow$ \\
Anemia & Hematocrit $\downarrow$, hemoglobin content $\downarrow$ \\
Metabolism and nutrition disorders & \\
Anorexia & Food intake $\downarrow$, non-feeding \\
Hypokalemia & Potassium $\downarrow$ \\
Dehydration & Dehydration \\
Hypoalbuminemia & Blood albumin $\downarrow$
\end{tabular}

Musculoskeletal, and connective tissue disorders

Intracranial hemorrhage

Bleeding in the brain

Gastrointestinal disorders

Constipation

Abnormal feces, feces $\downarrow$, no feces

Vomiting

Vomit

Diarrhea

Soft feces, diarrhea

Gastritis

Hemorrhage in gastric mucosa

Bleeding peptic ulcer

Hemorrhage in gastric mucosa

Skin and subcutaneous tissue disorders

Rash

Rash in hind limb skin

General disorders and administration-site conditions

Fatigue

Fever

Reduced activity

Adynamia

Fever

Investigations

Decrease in hematocrit

Decrease in hemoglobin

Decrease in phosphorus blood level

Decrease in blood potassium level

Reduced activity

Decrease in CD4 lymphocytes

Lymphocyte count decreased

WBC count $\downarrow$

Body weight $\downarrow$

RBC count $\downarrow$

Reticulocyte count decreased

Platelet count decreased

Neutropenia

Increase in alanine aminotransferase

Decrease in blood albumin level

Decrease in alkaline phosphatase

Transaminases increased

Decrease in hematocrit level

Decrease in hemoglobin, decrease in hemoglobin level Decrease in phosphorus

Potassium $\downarrow$

Lymphocytes $\downarrow$

Lymphocytes $\downarrow$

WBC count $\downarrow$, cell density of bone marrow $\downarrow$

Body weight $\downarrow$

RBC count $\downarrow$

RBC count $\downarrow$

Platelet count $\downarrow$, cell density of bone marrow $\downarrow$

Neutrophils $\downarrow$

Alanine aminotransferase $\uparrow$

Blood albumin $\downarrow$

Alkaline phosphatase $\downarrow$

Aspartate aminotransferase $\uparrow$

Gamma-glutamyl transpeptidase $\uparrow$

Increase in gamma-glutamyl transpeptidase

$W B C$ white blood cell, $\uparrow$ increased, $\downarrow$ decreased 
Table 4 NOAEL, LOAEL, and pivotal studies

\begin{tabular}{|c|c|c|c|c|c|}
\hline \multirow[t]{2}{*}{ Drug } & \multicolumn{3}{|c|}{$\begin{array}{l}\text { NOAEL and LOAEL in the most sensitive } \\
\text { species }^{\text {a }}(\mathrm{mg} / \mathrm{kg} / \text { day) }\end{array}$} & \multicolumn{2}{|l|}{ Pivotal studies } \\
\hline & NOAEL & LOAEL & Study & Title & $\begin{array}{l}\text { Priority } \\
\text { number }\end{array}$ \\
\hline Alemtuzumab & ND & 3.0 & $\begin{array}{l}\text { 14- or 30-day repeated- } \\
\text { dose toxicity study in } \\
\text { monkeys }\end{array}$ & $\begin{array}{l}\text { A phase III study to evaluate the efficacy and safety of front-line } \\
\left.\text { therapy with alemtuzumab (Campath }{ }^{\circledR} \text {, MabCampath }{ }^{\circledR}\right) \text { vs. } \\
\text { chlorambucil in patients with progressive B cell chronic } \\
\text { lymphocytic leukemia }\end{array}$ & 7 \\
\hline $\begin{array}{l}\text { Anagrelide } \\
\text { hydrochloride } \\
\text { hydrate }\end{array}$ & 0.3 & 3.0 & $\begin{array}{l}\text { 1-month repeated-dose } \\
\text { toxicity study in dogs }\end{array}$ & $\begin{array}{l}\text { A phase III, open-label, single-arm study evaluating the effect of } \\
\text { SPD422 on platelet lowering and safety in Japanese adults } \\
\text { with at risk essential thrombocythemia who are intolerant or } \\
\text { refractory to current cytoreductive treatment }\end{array}$ & 1 \\
\hline Azacitidine & 0.2 & 0.4 & $\begin{array}{l}\text { 2-week repeated-dose } \\
\text { toxicity study in dogs }\end{array}$ & $\begin{array}{l}\text { A phase I/II study of NS-17 in patients with myelodysplastic } \\
\text { syndrome }\end{array}$ & 4 \\
\hline $\begin{array}{l}\text { Bendamustine } \\
\text { hydrochloride }\end{array}$ & 1.65 & 3.3 & $\begin{array}{l}\text { 15-week repeated-dose } \\
\text { toxicity study in dogs }\end{array}$ & $\begin{array}{l}\text { An integration analysis of phase I study of SyB L-0501in patients } \\
\text { with low-grade B-cell non-Hodgkin lymphoma and phase II } \\
\text { study of SyB L-0501 in patients with low-grade B-cell non- } \\
\text { Hodgkin lymphoma and mantle cell lymphoma }\end{array}$ & 4 \\
\hline Bexarotene & 1.0 & 3.0 & $\begin{array}{l}\text { 39-week repeated-dose } \\
\text { toxicity study in dogs }\end{array}$ & $\begin{array}{l}\text { A phase I/II study of Tagretin }{ }^{\circledR} \text { capsules (BSC-1) in Japanese } \\
\text { patients with refractory cutaneous T-cell lymphoma }\end{array}$ & 4 \\
\hline Bortezomib & 0.045 & 0.067 & $\begin{array}{l}\text { 4-week repeated-dose } \\
\text { toxicity study in } \\
\text { monkeys }\end{array}$ & $\begin{array}{l}\text { An international, multi-center, randomized, open-label study of } \\
\text { PS-341 vs. high-dose dexamethasone in patients with relapsed } \\
\text { or refractory multiple myeloma }\end{array}$ & 7 \\
\hline Bosutinib & 5.0 & $\mathrm{NA}^{\mathrm{b}}$ & $\begin{array}{l}\text { 1-month repeated-dose } \\
\text { toxicity study in dogs }\end{array}$ & $\begin{array}{l}\text { A phase I/II study of SKI- } 606 \text { administered as a single agent in } \\
\text { Japanese subjects with Philadelphia chromosome-positive } \\
\text { leukemia }\end{array}$ & 3 \\
\hline $\begin{array}{l}\text { Brentuximab } \\
\text { vedotin }\end{array}$ & 0.5 & 5.0 & $\begin{array}{l}\text { 4-week repeated dose } \\
\text { toxicity study in rats }\end{array}$ & $\begin{array}{l}\text { A phase I/II, single-arm, open-label study of SGN-35 in Japanese } \\
\text { patients with relapsed refractory CD30-positive Hodgkin } \\
\text { lymphoma or systemic anaplastic large-cell lymphoma }\end{array}$ & 4 \\
\hline Cladribine & 0.1 & 0.3 & $\begin{array}{l}\text { 2-week repeated-dose } \\
\text { toxicity study in } \\
\text { monkeys }\end{array}$ & A phase II study in patients with hairy cell leukemia & 2 \\
\hline Clofarabine & 0.375 & 0.75 & $\begin{array}{l}\text { 6-month repeated-dose } \\
\text { toxicity study in dogs }\end{array}$ & $\begin{array}{l}\text { A phase II open-label study of clofarabine in pediatric patients } \\
\text { with refractory/relapsed acute lymphoblastic leukemia }\end{array}$ & 8 \\
\hline $\begin{array}{c}\text { Dasatinib } \\
\text { hydrate }\end{array}$ & 0.9 & 15 & $\begin{array}{l}\text { 1-month repeated-dose } \\
\text { toxicity study in rats }\end{array}$ & $\begin{array}{l}\text { A phase I/II study of BMS-354825 in patients with chronic phase } \\
\text { Philadelphia chromosome-positive chronic myeloid leukemia } \\
\text { and acute lymphatic leukemia }\end{array}$ & 3 \\
\hline $\begin{array}{r}\text { Fludarabine } \\
\text { phosphate }\end{array}$ & 1 & 10 & $\begin{array}{l}\text { 13-week repeated-dose } \\
\text { toxicity study in dogs }\end{array}$ & A phase II study in patients with chronic lymphatic leukemia & 2 \\
\hline $\begin{array}{r}\text { Gemtuzumab } \\
\text { ozogamicin }\end{array}$ & 0.12 & 0.47 & $\begin{array}{l}\text { 4-week repeated-dose } \\
\text { toxicity study in rats }\end{array}$ & $\begin{array}{l}\text { A phase II study in patients with initial relapse CD33-positive } \\
\text { acute myelocytic leukemia }\end{array}$ & 8 \\
\hline Ibrutinib & 12 & 36 & $\begin{array}{l}\text { 2-week repeated-dose } \\
\text { toxicity study in rats }\end{array}$ & $\begin{array}{l}\text { A randomized, multicenter, open-label, phase III study of } \\
\text { Bruton's tyrosome kinase inhibitor ibrutinib vs. ofatumumab in } \\
\text { patients with relapsed or refractory chronic lymphocytic } \\
\text { leukemia/small lymphocytic lymphoma }\end{array}$ & 7 \\
\hline $\begin{array}{l}\text { Imatinib } \\
\text { mesylate }\end{array}$ & 3 & 10 & $\begin{array}{l}\text { 13-week repeated-dose } \\
\text { toxicity study in dogs }\end{array}$ & $\begin{array}{l}\text { A phase I/II study in patients with } \mathrm{Ph}+\text { chronic-phase chronic } \\
\text { myeloid leukemia }\end{array}$ & 3 \\
\hline $\begin{array}{l}\text { Lenalidomide } \\
\text { hydrate }\end{array}$ & 2 & 4 & $\begin{array}{l}\text { 52-week repeated-dose } \\
\text { toxicity study in } \\
\text { monkeys }\end{array}$ & $\begin{array}{l}\text { A multicenter, randomized, parallel-group, double-blind, } \\
\text { placebo-controlled study of CC-5013 plus dexamethasone vs. } \\
\text { dexamethasone alone in previously treated subjects with } \\
\text { multiple myeloma }\end{array}$ & 7 \\
\hline Mogamulizumab & 40 & $\mathrm{NA}^{\mathrm{b}}$ & $\begin{array}{l}\text { 13-week repeated-dose } \\
\text { toxicity study in } \\
\text { monkeys }\end{array}$ & $\begin{array}{l}\text { An open-label, uncontrolled study in patients with recurrent or } \\
\text { relapsed CCR4-positive Adult T-cell leukemia }\end{array}$ & 2 \\
\hline Nelarabine & 10 & 20 & $\begin{array}{l}\text { 30-day repeated dose } \\
\text { toxicity study in } \\
\text { monkeys }\end{array}$ & $\begin{array}{l}\text { A phase II study of nelarabine (506U78) in patients with } \\
\text { refractory or relapsed T-lineage acute lymphoblastic leukemia } \\
\text { or lymphoblastic lymphoma }\end{array}$ & 8 \\
\hline
\end{tabular}


Table 4 continued

\begin{tabular}{|c|c|c|c|c|c|}
\hline \multirow[t]{2}{*}{ Drug } & \multicolumn{3}{|c|}{$\begin{array}{l}\text { NOAEL and LOAEL in the most sensitive } \\
\text { species }^{\mathrm{a}}(\mathrm{mg} / \mathrm{kg} / \text { day })\end{array}$} & \multicolumn{2}{|l|}{ Pivotal studies } \\
\hline & NOAEL & LOAEL & Study & Title & $\begin{array}{l}\text { Priority } \\
\text { number }^{\mathrm{c}}\end{array}$ \\
\hline $\begin{array}{l}\text { Nilotinib } \\
\text { hydrochloride } \\
\text { hydrate }\end{array}$ & 5 & 15 & $\begin{array}{l}\text { 4-week repeated-dose } \\
\text { toxicity study in dogs }\end{array}$ & $\begin{array}{l}\text { A phase IA/II multicenter, dose-escalation study of oral } \\
\text { AMN107 on a continuous daily dosing schedule in adult } \\
\text { patients with Glivec }{ }^{\circledR} \text { (imatinib)-resistant/intolerant chronic } \\
\text { myeloid leukemia in chronic or accelerated phase or blast } \\
\text { crisis, relapse/refractory Ph }+\mathrm{A}++ \text {, and other hematologic } \\
\text { malignancies (CAMN1072101 phase II component) }\end{array}$ & 3 \\
\hline Ofatumumab & 100 & $\mathrm{NA}^{\mathrm{b}}$ & $\begin{array}{l}\text { 7-month repeated-dose } \\
\text { toxicity study in } \\
\text { monkeys }\end{array}$ & $\begin{array}{l}\text { A single-arm, international, multi-center trial of HuMax-CD20, a } \\
\text { fully human monoclonal anti-CD20 antibody, in patients with } \\
\text { B-cell chronic lymphocytic leukemia who have failed } \\
\text { fludarabine and alemtuzumab }\end{array}$ & 8 \\
\hline $\begin{array}{l}\text { Panobinostat } \\
\text { lactate }\end{array}$ & 0.15 & 0.5 & $\begin{array}{l}\text { 39-week repeated-dose } \\
\text { toxicity study in dogs }\end{array}$ & $\begin{array}{l}\text { A multicenter, randomized, double-blind, placebo-controlled } \\
\text { phase III study of panobinostat in combination with bortezomib } \\
\text { and dexamethasone in patients with relapsed multiple myeloma }\end{array}$ & 5 \\
\hline Pomalidomide & 0.1 & 1 & $\begin{array}{l}\text { 9-month repeated-dose } \\
\text { toxicity study in } \\
\text { monkeys }\end{array}$ & $\begin{array}{l}\text { A phase II, multicenter, single-arm, open-label study in Japan to } \\
\text { evaluate the efficacy and safety of pomalidomide (CC-4047) in } \\
\text { combination with dexamethasone in subjects with relapsed and } \\
\text { refractory multiple myeloma }\end{array}$ & 2 \\
\hline Rituximab & 20 & $\mathrm{NA}^{\mathrm{b}}$ & $\begin{array}{l}\text { 2-month repeated-dose } \\
\text { toxicity study in } \\
\text { monkeys }\end{array}$ & $\begin{array}{l}\text { A phase II, repeated-dose study of IDEC-C2B8 in patients with } \\
\text { relapse/recurrent or treatment-resistant indolent B-cell } \\
\text { lymphoma }\end{array}$ & 2 \\
\hline $\begin{array}{r}\text { Ruxolitinib } \\
\text { phosphate }\end{array}$ & 0.1 & 1 & $\begin{array}{l}\text { 9-month repeated-dose } \\
\text { toxicity study in } \\
\text { monkeys }\end{array}$ & $\begin{array}{l}\text { A multi-national, open-label, phase II study of the JAK inhibitor } \\
\text { INC424 in patients with primary myelofibrosis, post- } \\
\text { polycythemia vera myelofibrosis, or post-essential } \\
\text { thrombocythemia myelofibrosis }\end{array}$ & 6 \\
\hline Tamibarotene & 0.016 & 0.08 & $\begin{array}{l}\text { 4-week repeated-dose } \\
\text { toxicity study in rats }\end{array}$ & $\begin{array}{l}\text { A late phase II study in patients with acute promyelocytic } \\
\text { leukemia }\end{array}$ & 2 \\
\hline Thalidomide & 30 & 300 & $\begin{array}{l}\text { 13-week repeated-dose } \\
\text { toxicity study in rats }\end{array}$ & $\begin{array}{l}\text { A multi-center, open-label, dose-escalation study in patients with } \\
\text { multiple myeloma relapsing after hematopoietic stem cell } \\
\text { transplantation or with chemotherapy-resistant multiple } \\
\text { myeloma }\end{array}$ & 2 \\
\hline Vorinostat & 20 & 50 & $\begin{array}{l}\text { 4-week repeated-dose } \\
\text { toxicity study in rats }\end{array}$ & $\begin{array}{l}\text { A phase IIb multicenter clinical trial of oral suberoylanilide } \\
\text { hydroxamic acid in advanced cutaneous T-cell lymphoma }\end{array}$ & 8 \\
\hline
\end{tabular}

$\overline{J A K}$ janus kinase, LOAEL lowest observed adverse effect level, $N A$ not available, $N D$ not detected, NOAEL no observed adverse effect level

a Animal species that gives the smallest NOAEL

b Dose over NOAEL was not investigated

${ }^{c}$ Refer to Table 2

\section{Discussion}

The purpose of our study was to analyze the potential of nonclinical safety assessments in predicting ADRs in humans. We obtained the nonclinical toxicological findings and ADRs observed in clinical trials for each drug and examined the relationship of safety levels for animals and humans by calculating the concordance rates. In similar studies, the JPMA conducted systematic and retrospective surveys to analyze the concordance of toxicity in animal tests and ADRs in clinical trials $[15,16]$. Igarashi et al. investigated 141 drugs approved in Japan [6]. They showed that general pharmacological studies of cardiovascular functions, spontaneous locomotor activity, and intestinal transport were useful in predicting ADRs [6]. More recently, Tamaki et al. conducted a study to examine the usefulness of nonclinical safety assessments in predicting ADRs in humans [17]. They revealed that $37 \%$ of ADRs were predictable based on concordant toxicological findings in animals [17]. This figure is slightly higher than the mean concordance rate of our study (23.9\%). However, considering that they targeted all drugs, excluding anticancer agents and vaccines, and collected ADRs with an incidence rate of $\geq 5 \%$, these figures are comparable.

In a further investigation, we analyzed the correlation between the concordance rate and the quantitative safety profile obtained in our previous study [4]. As shown in Fig. 3, there was a significant correlation between these 
Table 5 Concordance rate, administration route, drug type, and quantitative safety profile

\begin{tabular}{|c|c|c|c|c|c|c|c|c|c|c|c|c|c|}
\hline \multicolumn{2}{|l|}{ Drug } & \multicolumn{2}{|c|}{ Concordance rate $(\%)$} & \multicolumn{2}{|c|}{ Administration route } & \multicolumn{2}{|c|}{ Drug type } & \multicolumn{2}{|c|}{ Species $^{\mathrm{a}}$} & \multicolumn{4}{|c|}{$\begin{array}{l}\text { Quantitative safety } \\
\text { profile }\left(\text { SI-D }^{\mathrm{b}}, \text { SI-C }^{\mathrm{c}}, \text { SI-A }\right.\end{array}$} \\
\hline \multicolumn{2}{|l|}{ Alemtuzumab } & \multicolumn{2}{|l|}{$34.3^{\mathrm{e}}$} & \multicolumn{2}{|c|}{ Injection } & \multicolumn{2}{|c|}{ Antibody } & \multicolumn{2}{|c|}{ Monkey } & \multicolumn{4}{|c|}{ NA (NA, NA, NA) } \\
\hline \multicolumn{2}{|c|}{ Anagrelide Hydrochloride hydrate } & \multicolumn{2}{|l|}{$0^{\mathrm{e}}$} & \multicolumn{2}{|l|}{ Oral } & \multicolumn{2}{|l|}{ SM } & \multicolumn{2}{|l|}{ Dog } & \multicolumn{4}{|c|}{ III $(>1.0,<1.0,<1.0)$} \\
\hline \multicolumn{2}{|l|}{ Azacitidine } & \multicolumn{2}{|l|}{$84.8^{\mathrm{e}}$} & \multicolumn{2}{|c|}{ Injection } & \multicolumn{2}{|l|}{ SM } & \multicolumn{2}{|l|}{ Dog } & \multicolumn{4}{|c|}{$\mathrm{V}(<1.0,<1.0,<1.0)$} \\
\hline \multicolumn{2}{|c|}{ Bendamustine hydrochloride } & $65.0^{\mathrm{e}}$ & & Injectio & & SM & & Dog & & $\mathrm{V}(<1$ & $.0, \mathrm{NA}$, & $<1.0)$ & \\
\hline Bexarotene & & $0^{\mathrm{e}}$ & & Oral & & $\mathrm{SM}$ & & Dog & & $\mathrm{V}(<1$ & $.0,<1.0$, & $<1.0$ & \\
\hline Bortezomib & & $13.0^{\mathrm{e}}$ & & Injectio & & SM & & Monl & & NA $(>$ & $1.0, \mathrm{NA}$ & NA) & \\
\hline Bosutinib & & NA & & Oral & & $\mathrm{SM}$ & & Dog & & IV $(<$ & $1.0,>1.0$ & $>1$. & \\
\hline Brentuximab Vedotin & & $76.2^{\mathrm{e}}$ & & Injectio & & Antil & ody & Rat & & $\mathrm{V}(<1$ & $.0,<1.0$, & NA) & \\
\hline Cladribine & & $28.0^{\mathrm{e}}$ & & Injectio & & SM & & Monl & & NA $(>$ & $1.0, \mathrm{NA}$ & NA) & \\
\hline Clofarabine & & $17.9^{\mathrm{e}}$ & & Injectio & & SM & & Dog & & $\mathrm{V}(<1$ & $.0,<1.0$, & $<1.0$ & \\
\hline Dasatinib hydrate & & $26.7^{\mathrm{e}}$ & & Oral & & $\mathrm{SM}$ & & Rat & & $\mathrm{V}(<1$ & $.0,<1.0$, & $<1.0$ & \\
\hline Fludarabine phosphate & & $15.4^{\mathrm{e}}$ & & Injectio & & SM & & Dog & & NA $(>$ & $1.0, \mathrm{NA}$ & NA) & \\
\hline Gemtuzumab ozogami & & $21.8^{\mathrm{e}}$ & & Injectio & & Antil & ody & Rat & & $\mathrm{V}(<1$ & $.0,<1.0$, & NA) & \\
\hline Ibrutinib & & $2.1^{\mathrm{e}}$ & & Oral & & $\mathrm{SM}$ & & Rat & & NA $(>$ & $1.0, \mathrm{NA}$ & NA) & \\
\hline Imatinib mesilate & & $50.0^{\mathrm{e}}$ & & Oral & & SM & & Dog & & $\mathrm{V}(<1$ & $.0,<1.0$, & $<1.0$ & \\
\hline Lenalidomide hydrate & & $22.1^{\mathrm{e}}$ & & Oral & & $\mathrm{SM}$ & & Monl & & $\mathrm{I}(>1$. & $0,>1.0$ & $>1.0)$ & \\
\hline Mogamulizumab & & $6.8^{\mathrm{f}}$ & & Injectio & & Antil & ody & Monl & & $\mathrm{I}(>1$. & $0, \mathrm{NA},>$ & $1.0)$ & \\
\hline Nelarabine & & $44.4^{\mathrm{e}}$ & & Injectio & & SM & & Monl & & $\mathrm{V}(<1$ & $.0, \mathrm{NA}$, & $<1.0)$ & \\
\hline Nilotinib Hydrochlorid & e hydrate & $1.2^{\mathrm{e}}$ & & Oral & & SM & & Dog & & $\mathrm{V}(<1$ & $.0,<1.0$, & $<1.0$ & \\
\hline Ofatumumab & & $0.7^{\mathrm{f}}$ & & Injectio & & Antil & ody & Monl & & $\mathrm{I}(>1$ & $0,>1.0$ & $>1.0)$ & \\
\hline Panobinostat Lactate & & $19.1^{\mathrm{e}}$ & & Oral & & SM & & Dog & & $\mathrm{V}(<1$ & $.0,<1.0$, & $<1.0$ & \\
\hline Pomalidomide & & $6.8^{\mathrm{e}}$ & & Oral & & SM & & Monl & & III $(>$ & $1.0,<1.0$ & $<1.0$ & \\
\hline Rituximab & & $0^{\mathrm{f}}$ & & Injectio & & Antil & ody & Monl & & III $(>$ & $1.0,<1.0$ & NA) & \\
\hline Ruxolitinib Phosphate & & $48.6^{\mathrm{e}}$ & & Oral & & SM & & Dog & & III $(>$ & $1.0,<1.0$ & $<1.0$ & \\
\hline Tamibarotene & & $0^{\mathrm{e}}$ & & Oral & & SM & & Rat & & NA $(<$ & <1.0, NA & NA) & \\
\hline Thalidomide & & $0^{\mathrm{e}}$ & & Oral & & SM & & Rat & & I $(>1$. & $0,>1.0$ & $>1.0)$ & \\
\hline Vorinostat & & $36.8^{\mathrm{e}}$ & & Oral & & SM & & Rat & & III $(>$ & 1.0, NA, & $<1.0)$ & \\
\hline Concordance rate $(\%)$ & All & Drug type & & Administ & tion route & Species & & & $\mathrm{Qu}$ & ntitative & safety $\mathrm{p}$ & rofile & \\
\hline & & SM & Antibody & Injection & Oral & Rodents & Non- & dents & I & II & III & IV & $\mathrm{V}$ \\
\hline$n^{\mathrm{g}}$ & 26 & 20 & 6 & 13 & 13 & 7 & 19 & & 4 & 0 & 5 & 0 & 11 \\
\hline Range & $0-84.8$ & $0-84.8$ & $0-76.2$ & $0-84.8$ & $0-50.1$ & $0-76.2$ & $0-84$ & & 0 & 2.1 & $0-48.6$ & & $0-84.8$ \\
\hline Mean (SD) & $23.9(24.8)$ & $24.1(24.2)$ & $\begin{array}{l}23.3 \\
(29.1)\end{array}$ & $\begin{array}{l}31.4 \\
(28.3)\end{array}$ & $\begin{array}{l}16.4 \\
(19.0)\end{array}$ & $\begin{array}{l}24.7 \\
(25.7)\end{array}$ & $\begin{array}{l}23.6 \\
(25.1\end{array}$ & & $\begin{array}{l}7.4 \\
(10\end{array}$ & & $\begin{array}{l}18.4 \\
(22.7)\end{array}$ & & $\begin{array}{l}37.0 \\
(29.2)\end{array}$ \\
\hline Median & 18.5 & 18.5 & 14.3 & 21.8 & 6.8 & 24.3 & 16.7 & & 3.8 & & 6.8 & & 26.7 \\
\hline
\end{tabular}

$\overline{A D R s}$ adverse drug reactions, $A E s$ adverse events, $A U C$ area under the plasma concentration-time curve, $C_{\max }$ maximum plasma concentration, $N A$ not available, NOAEL no observed adverse effect level, $S D$ standard deviation, $S M$ small molecule

${ }^{a}$ Animal species that gives the smallest NOAEL

${ }^{\mathrm{b}}$ SI-D $=$ NOAEL $(\mathrm{mg} / \mathrm{kg} /$ day $) /$ the maximum approved dose $(\mathrm{mg} / \mathrm{kg} /$ day $)$

${ }^{c}$ SI-C $=C_{\max }$ at NOAEL $(\mu \mathrm{g} / \mathrm{mL}) / C_{\max }$ at the maximum approved dose $(\mu \mathrm{g} / \mathrm{mL})$

${ }^{\mathrm{d}} \mathrm{SI}-\mathrm{A}=\mathrm{AUC}$ at NOAEL $(\mu \mathrm{g} \cdot \mathrm{h} / \mathrm{mL}) / \mathrm{AUC}$ at the maximum approved dose $(\mu \mathrm{g} \cdot \mathrm{h} / \mathrm{mL})$

${ }^{\mathrm{e}}$ Concordance rate $(\%)=$ (number of ADRs or AEs of $\geq$ grade 3 that are concordant with toxicological findings at LOAEL/total number of ADRs or AEs of $\geq$ grade 3$) \times 100$

${ }^{\mathrm{f}}$ Concordance rate $(\%)=$ (number of ADRs or AEs of $\leq$ grade 1 that are concordant with nontoxic observations at NOAEL/total number of ADRs or AEs of $\leq$ grade 1$) \times 100$

g Excluding bosutinib 
Table 6 Concordance rate of each System Organ Class categorized by CTCAE

\begin{tabular}{|c|c|c|c|c|c|c|c|c|c|}
\hline System Organ Class ${ }^{\mathrm{a}}$ (drug) & A & $\mathrm{B}$ & $\mathrm{C}$ & $\mathrm{D}$ & $\mathrm{E}$ & $\mathrm{F}$ & G & $\mathrm{H}$ & Total $(\%)$ \\
\hline Alemtuzumab & & & & & & & 34.3 & & 34.3 \\
\hline Anagrelide hydrochloride hydrate & & & & & & & & & 0 \\
\hline Azacitidine & 0.7 & 59.9 & 0.7 & 0.3 & & & & 23.2 & 84.8 \\
\hline Bendamustine hydrochloride & & 2.1 & 0.7 & 11.0 & & & & 61.1 & 65.0 \\
\hline Bexarotene & & & & & & & & & 0 \\
\hline Bortezomib & & 7.3 & 1.8 & 3.1 & 0.9 & & & & 13.0 \\
\hline Bosutinib & & & & & & & & & NA \\
\hline Brentuximab vedotin & & 76.2 & & & & & & & 76.2 \\
\hline Cladribine & & 28.0 & & & & & & & 28.0 \\
\hline Clofarabine & & 6.0 & 2.6 & 6.0 & & & & 3.4 & 18.0 \\
\hline Dasatinib hydrate & & 6.2 & & & & & & 20.5 & 26.7 \\
\hline Fludarabine phosphate & & & & & & & & 15.4 & 15.4 \\
\hline Gemtuzumab ozogamicin & & 9.1 & 0.3 & & & & & 12.4 & 21.8 \\
\hline Ibrutinib & & 2.1 & & & & & & & 2.1 \\
\hline Imatinib mesylate & & 4.8 & & & & & & 45.2 & 50.0 \\
\hline Lenalidomide hydrate & & 13.5 & 0.2 & 1.3 & & 0.2 & 5.2 & 1.7 & 22.1 \\
\hline Mogamulizumab & & & & & & & & 6.8 & 6.8 \\
\hline Nelarabine & & & & & & & & 44.4 & 44.4 \\
\hline Nilotinib hydrochloride hydrate & & & & & & & & 1.2 & 1.2 \\
\hline Ofatumumab & & 0.7 & & & & & & & 0.7 \\
\hline Panobinostat lactate & & 16.6 & & & & & & 2.5 & 19.1 \\
\hline Pomalidomide & & 4.5 & & & & & & 2.3 & 6.8 \\
\hline Rituximab & & & & & & & & & 0 \\
\hline Ruxolitinib phosphate & & 46.8 & & & & & & 1.8 & 48.6 \\
\hline Tamibarotene & & & & & & & & & 0 \\
\hline Thalidomide & & & & & & & & & 0 \\
\hline Vorinostat & & 21.1 & 10.5 & & & & & 5.3 & 36.9 \\
\hline
\end{tabular}

CTCAE Common Terminology Criteria for Adverse Events, NA not available

${ }^{a}$ System Organ Class: A: Infections and infestations; B: Blood and lymphatic system disorders; C: Metabolism and nutrition disorders; D: Gastrointestinal disorders; E: Skin and subcutaneous tissue disorders; F: Musculoskeletal, and connective tissue disorders; G: General disorders and administration site conditions; H: Investigations

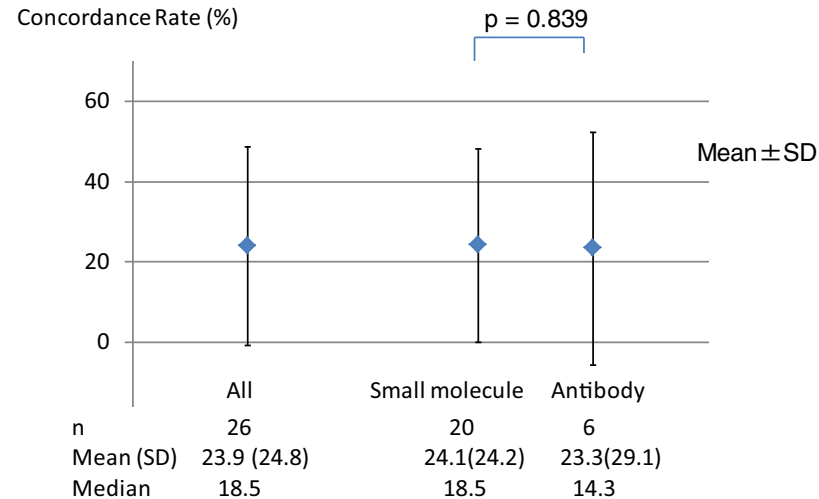

Fig. 2 Concordance rates of all, small-molecule, and antibody drugs. $S D$ standard deviation

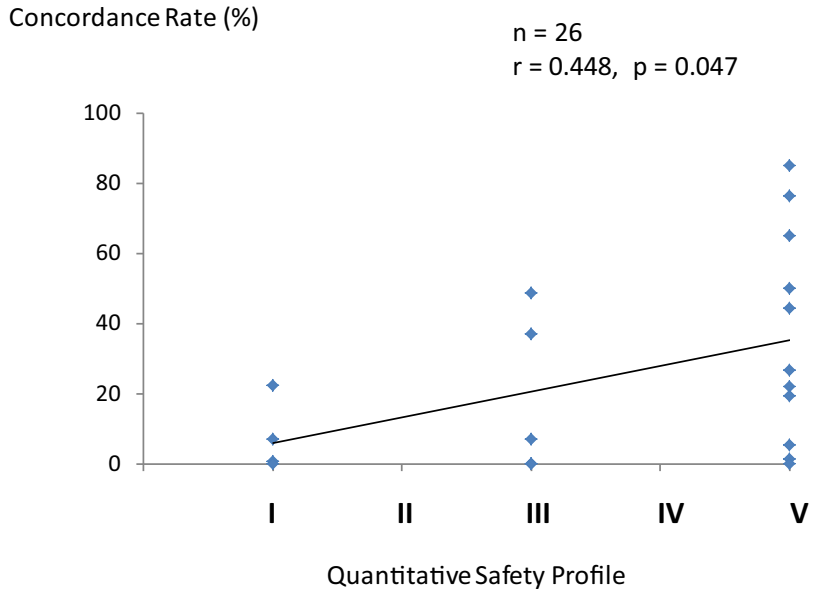

Fig. 3 Correlation between concordance rate and quantitative safety profile 
two factors. As the concordance rate varied over a wide range, from 0 to $84.8 \%$, it was difficult to predict clinical ADRs in a comprehensive manner based on animal toxicological findings. However, a significant correlation between the concordance rate and the quantitative safety profile indicated that drugs with a low quantitative safety profile would show relatively high concordance rates. Examination of animal toxicological findings, especially for drugs with a low quantitative safety profile, has the potential to predict their clinical safety. For drugs with the quantitative safety profile of category III, IV, or V, the dose and/or exposure at clinical therapeutic use exceeded the dose/exposure at NOAEL. Therefore, some animal toxicological findings at LOAEL for such drugs might be reproducible in clinical use. If the toxicological finding at LOAEL is not available, the observations at NOAEL might provide useful information and help to predict ADRs to some extent. However, considering that the mean concordance rates of drugs with a high quantitative safety profile (category I: 7.4\%) were lower than those of drugs with a low safety profile (category III: $18.4 \%$, or category V: $37.0 \%$ ), the overall risk-benefit of those drugs should be carefully considered, taking into account various aspects. When looking at concordance rates by SOC, ADRs concordant with nonclinical observations in blood and lymphatic system disorders and investigations were found for approximately $60 \%$ of the drugs in this study. In terms of blood cancer drugs, toxicological findings related to those SOCs might provide beneficial information to predict clinical ADRs in those SOCs.

We found that the median concordance rate of antibody drugs $(14.3 \%)$ was lower than that of small-molecule drugs $(18.5 \%)$, although there was no significant difference between them and the number of antibodies was small. Tamaki et al. reported that the proportion of correlated ADRs in small-molecule drugs was $46 \%$ and that in antibody drugs was $16 \%$, indicating a trend similar to that of our results [17]. For small molecules, general toxicology tests are usually performed in rodents and non-rodents (ICH S9) [18]. However, ICH S6 [19] states that safety evaluation programs for biotechnology-derived pharmaceuticals should normally include two relevant species, but in certain justified cases, one relevant species may suffice. According to the ICH S6 guideline, the animal species for testing of monoclonal antibodies are those that express the desired epitope and demonstrate a similar tissue cross-reactivity profile as for human tissues.

In our study, four of the six antibody drugs had nonclinical data only for monkeys, and other species were not investigated. This might have contributed to the low concordance rate. Chapman et al. discussed the selection of species for toxicology studies of monoclonal antibodies [20]. They raised the concern that species cross-reactivity alone might not be sufficient to confirm species suitability. They referred to the case of TGN412, an anti-CD28 superagonist monoclonal antibody, which induced a life-threatening cytokine storm in its first human study. Although there was no significant difference in concordance rates between antibody and small-molecule drugs, an appropriate way to predict the risk to humans, based on nonclinical toxicity findings for antibody drugs, is still needed. In 2014, seven of the top ten best-selling drugs in the world were biotechnology-derived pharmaceuticals [21] and many more biopharmaceutical products are under development [22]. Therefore, practical guidance for a risk-benefit assessment of biopharmaceuticals would be beneficial.

There is currently no established method to weigh the predictability of ADRs in humans on the basis of animal data. Bailey et al. conducted several studies on human drug safety using toxicity data obtained from animal tests [23-25]. They suggested that toxicity observed in animals occurs in humans. However, their data were not particularly consistent or reliable because of considerable variability and the lack of any clear pattern in the types of toxic effects. They overlooked the caveat that the absence of toxicity in animals provided essentially no insight into the likelihood of toxicity or absence of toxicity in humans. Perel et al. compared treatment effects reported in systematic reviews of clinical trials with those of their own systematic review of the corresponding animal experiments [26]. They concluded that many animal studies are of poor methodological quality and the lack of concordance between animal experiments and clinical trials is the result of bias, random error, or the failure of animal models to adequately represent human diseases.

Although we investigated all blood cancer drugs approved in Japan from 1999 to date, there is a limitation in publicly available data. Access to some of the existing data was not possible because study reports in CTD M4 and M5 were not disclosed; only summary documents, such as CTD M2, are available. The amount of information available for different drugs varies; some CTD M2 documents contain enough data for analysis but others do not. Moreover, as we focused on drugs for blood cancer, caution should be taken when generalizing about drugs used in other therapeutic areas.

We found that the potential range of applications of nonclinical assessments in ADR predictions was substantial. However, our concordance rates differed from those reported in some other studies. Our analysis of the relationship between concordance rate and quantitative safety profile found a weak correlation, suggesting that ADRs are predictable on the basis of animal toxicities, especially for some drugs with low quantitative safety profiles. Perel et al. suggested that with the increasing number of systematic reviews of animal experiments, a quantitative 
approach to determine similarities between animal models and clinical trials should become possible [26]. Our study results should contribute to the development of this field.

\section{Conclusion}

Within the constraints of this study, our results suggest that toxicity findings observed in animal tests could be extrapolated to human treatments. This might allow the prediction of ADRs in clinical trials for some drugs with a low quantitative safety profile. Nonclinical safety assessments might be useful in predicting the clinical safety of such drugs.

\section{Compliance with ethical standards}

Funding No sources of funding were used to conduct this study or prepare this manuscript.

Conflict of interest Sachie Kubota, Kazuyuki Saito, Shunsuke Ono, and Yasuo Kodama declare no conflict of interest associated with this manuscript.

Open Access This article is distributed under the terms of the Creative Commons Attribution-NonCommercial 4.0 International License (http://creativecommons.org/licenses/by-nc/4.0/), which permits any noncommercial use, distribution, and reproduction in any medium, provided you give appropriate credit to the original author(s) and the source, provide a link to the Creative Commons license, and indicate if changes were made.

\section{References}

1. ICH. Guidance on nonclinical safety studies for the conduct of human clinical trials and marketing authorization for pharmaceuticals M3(R2). Available from: http://www.ich.org/fileadmin/ Public_Web_Site/ICH_Products/Guidelines/Multidisciplinary/ M3_R2/Step4/M3_R2_Guideline.pdf. 2009. Accessed 11 Jul 2015.

2. ICH. General considerations for clinical trials E8. Available from http://www.ich.org/fileadmin/Public_Web_Site/ICH_Products/ Guidelines/Efficacy/E8/Step4/E8_Guideline.pdf. 1997. Accessed 23 Jul 2016

3. Kodama Y, Saito K, Ono S, et al. Utilisation of human pharmacology studies with biomarkers for new drug applications in Japan. Drugs R D. 2005;6:21-34.

4. Kubota S, Saito K, Ono S, Kodama Y. Evaluation of safety profiles of blood cancer drugs approved in Japan. Ther Innov Regul Sci. 2016;50:228-35.

5. ICH. Note for guidance on toxicokinetics: the assessment of systemic exposure in toxicity studies S3A. http://www.ich.org/ fileadmin/Public_Web_Site/ICH_Products/Guidelines/Safety/S3A/ Step4/S3A_Guideline.pdf. 1994. Accessed 23 Jul 2016.

6. Igarashi $\mathrm{T}$, Nakane $\mathrm{S}$, Kitagawa $\mathrm{T}$. Predictability of clinical adverse reactions of drugs by general pharmacology studies. J Toxicol Sci. 1995;20:77-92.

7. Olson H, Betton G, Robinson D, et al. Concordance of the toxicity of pharmaceuticals in humans and animals. Regul Toxicol Pharmacol. 2000;32:56-67.
8. ICH. Organization of the common technical documents for the registration of pharmaceuticals for human use. http://www.ich. org/fileadmin/Public_Web_Site/ICH_Products/CTD/M4_R3_ Organisation/M4_R3_organisation.pdf. 2004. Accessed 23 Jul 2016

9. MHLW. The standards for the conduct of clinical studies. MHLW Ministerial Ordinance No. 28; 27 March 1997.

10. MHLW. The ordinance on standards for conduct of nonclinical studies on the safety of drugs. MHLW Ministerial Ordinance No. 21; 26 March 1997.

11. National Cancer Institute - Common Toxicity Criteria. Version 2.0. http://ctep.cancer.gov/protocolDevelopment/electronic_applications/ docs/ctcv20_4-30-992.pdf. 1999. Accessed 19 May 2016.

12. Common Terminology Criteria for Adverse Events. Version 3.0. http://ctep.cancer.gov/protocolDevelopment/electronic_applications/ docs/ctcaev3.pdf. 2006. Accessed 19 May 2016.

13. Common Terminology Criteria for Adverse Events. Version 4.0. http://evs.nci.nih.gov/ftp1/CTCAE/CTCAE_4.03_2010-06-14_ QuickReference_5x7.pdf. 2009. Accessed 19 May 2016.

14. ICH. Ethnic factors in the acceptability of foreign clinical data E5(R1). http://www.ich.org/fileadmin/Public_Web_Site/ICH Products/Guidelines/Efficacy/E5_R1/Step4/E5_R1__Guideline. pdf. 1998. Accessed 12 Nov 2016.

15. JPMA. The relationship between toxicity testing results and clinical adverse reactions. Seiyakukyo Material No. 52, 1992.

16. JPMA. Questionnaire survey on the relationship between clinical adverse reactions and toxicity testing results. Seiyakukyo Material No. 61, 1993.

17. Tamaki C, Nagayama T, Hashiba M, et al. Potentials and limitations of nonclinical safety assessment for predicting clinical adverse drugs reactions: correlation analysis of 142 approved drugs in Japan. J Toxicol Sci. 2013;38:581-98.

18. ICH. Nonclinical evaluations for anticancer pharmaceuticals S9. http://www.ich.org/fileadmin/Public_Web_Site/ICH_Products/ Guidelines/Safety/S9/Step4/S9_Step4_Guideline.pdf. 2009. Accessed 23 Jul 2016.

19. ICH. Preclinical safety evaluation of biotechnology-derived pharmaceuticals S6(R1). http://www.ich.org/fileadmin/Public_ Web_Site/ICH_Products/Guidelines/Safety/S6_R1/Step4/S6_R1_ Guideline.pdf. 2011. Accessed 23 Jul 2016.

20. Chapman K, Pullen N, Graham M, Ragan I. Preclinical safety testing of monoclonal antibodies: the significance of species relevance. Nat Rev Drug Discov. 2007;6:120-6.

21. IMS Health MIDAS. Top 20 global products 2014. http://www. imshealth.com/files/web/Corporate/News/Top-Line\%20Market\% 20Data/2014/Top_20_Global_Products_2014.pdf. 2014. Accessed 19 May 2016.

22. Taylor D. The pharmaceutical industry and the future of drug development. Pharmaceuticals in the environment. 2015. p. 1-33. doi:10.1039/9781782622345-00001.

23. Bailey J, Thew M, Balls M. An analysis of the use of dogs in predicting human toxicology and drug safety. Altern Lab Anim. 2013;41:335-50.

24. Bailey J, Thew M, Balls M. An analysis of the use of animal models in predicting human toxicology and drug safety. Altern Lab Anim. 2014;42:181-9.

25. Bailey J, Thew M, Balls M. Predicting human drug toxicology and safety via animal tests: can any one species predict drug toxicity in any other, and do monkeys help? Altern Lab Anim. 2015;43:393-403.

26. Perel P, Roberts I, Sena E. Comparison of treatment effects between animal experiments and clinical trials: systematic review. BMJ. 2007;334(7586): 197.

27. Pharmaceuticals and Medical Devices Agency. http://www.pmda. go.jp. Accessed 4 Nov 2016. 